\title{
BMJ Open Burden of out-of-pocket payments among patients with cardiovascular disease in public and private hospitals in Ibadan, South West, Nigeria: a cross- sectional study
}

\author{
Folashayo Adeniji (D)
}

To cite: Adeniji F. Burden of out-of-pocket payments among patients with cardiovascular disease in public and private hospitals in Ibadan, South West, Nigeria: a crosssectional study. BMJ Open 2021;11:e044044. doi:10.1136/ bmjopen-2020-044044

- Prepublication history and supplemental material for this paper is available online. To view these files, please visit the journal online (http://dx.doi org/10.1136/bmjopen-2020044044).

Received 22 August 2020 Accepted 12 May 2021
Check for updates

(C) Author(s) (or their employer(s)) 2021. Re-use permitted under CC BY-NC. No commercial re-use. See rights and permissions. Published by BMJ.

Health Policy and Management, Faculty of Public Health, College of Medicine, University of Ibadan, Ibadan, Nigeria

Correspondence to Dr Folashayo Adeniji; folashayoadeniji@yahoo.co.uk

\section{ABSTRACT}

Objective Given that the mechanism for financial protection is underdeveloped in Nigeria, out-of-pocket (00P) payment for treating cardiovascular disease could impose substantial financial burden on individuals and their families. This study estimated the burden of OOP expenditures incurred by a cohort of patients with cardiovascular disease (CVD) in Ibadan, Nigeria. Design and settings This study used a descriptive cross-sectional study design. A standardised survey questionnaire originally developed by Initiative for Cardiovascular Health Research in Developing Countries was used to electronically collect data from all the 744 patients with CVD who accessed healthcare between 4 November 2019 and 31 January 2020 in the cardiology departments of private and public hospitals in Ibadan, Nigeria. Baseline characteristics of respondents were presented using percentages and proportions. The 00P payments were reported as means \pm SDs. Costs/OOP payments were in Nigerian Naira (NGN). The average US dollar to NGN at the time of data collection was $¥ 362.12$ per \$1. All quantitative data were analysed using STATA V.15.

Outcome measures The burden of outpatient, inpatient and rehabilitative care 00P payments.

Results Majority of the patients with CVD were within the age range of $45-74$ years and $68.55 \%$ of them were women. The diagnostic conditions reported among patients with CVD were hypertensive heart failure (84.01\%), dilated cardiomyopathy (4.44\%), ischaemic heart disease (3.9\%) and anaemic heart failure (2.15\%). Across all the hospital facilities, the annual direct and indirect outpatient costs were $\$ 421595.7 \pm 855962.0$ (\$1164.2 $\$$ \$2363.8) and $19146.5 \pm \$ 53610.1$ (\$52.87 $\$ 148.05$ ). Similarly, the average direct and indirect 00P payments per hospitalisation across all facilities were 182 $302.4 \pm 2249090.4(\$ 503.43 \pm \$ 687.87)$ and $\$ 14$

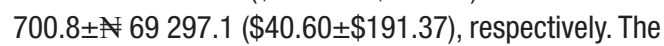
average rehabilitative cost after discharge from index hospitalisation was $\$ 30012.0$ (\$82.88).

Conclusion The burden of OOP payment among patients with CVD is enormous. There is a need to increase efforts to achieve universal health coverage in Nigeria.
Strengths and limitations of this study

- A microcosting approach was adopted to estimate the costs of accessing cardiovascular disease (CVD) treatment entirely from patients' perspective.

- The implementation of this study is methodologically robust as it attempted to avoid some of the weaknesses observed in previous studies conducted in Nigeria.

- A total sampling of all patients with CVD who attended general and specialised heart hospitals during the period of the study was carried out.

- The out-of-pocket payments elicited for hospitalised patients with CVD may have been underestimated since data were collected after the patients were discharged to avoid bogging them and/or their caregivers at a time when they were seriously ill and hospitalised.

- This study was a hospital-based study, and as a result, patients with CVD who did not visit the hospitals because of inability to pay were not captured in the study.

\section{BACKGROUND}

The prevalence of cardiovascular diseases (CVDs) is increasing in low-income andmiddle-income-countries (LMICs), imposing a substantial economic burden on economies, households and individuals. ${ }^{1-3}$ In many developing countries, CVDs are becoming the leading cause of morbidity and deaths. ${ }^{4}$ Recently, countries in sub-Saharan Africa (SSA) are experiencing an unprecedented rise in the number of individuals coming down with heart-related diseases. ${ }^{5-7}$ A study reported that this health condition accounts for between $7 \%$ and $9 \%$ of all hospital admissions in the African region. ${ }^{8}$ Between 1990 and 2017 , the number of deaths related to CVDs in SSA increased by over $50 \% .{ }^{9}{ }^{10}$

Furthermore, universal health coverage (UHC) remains low in majority of the 


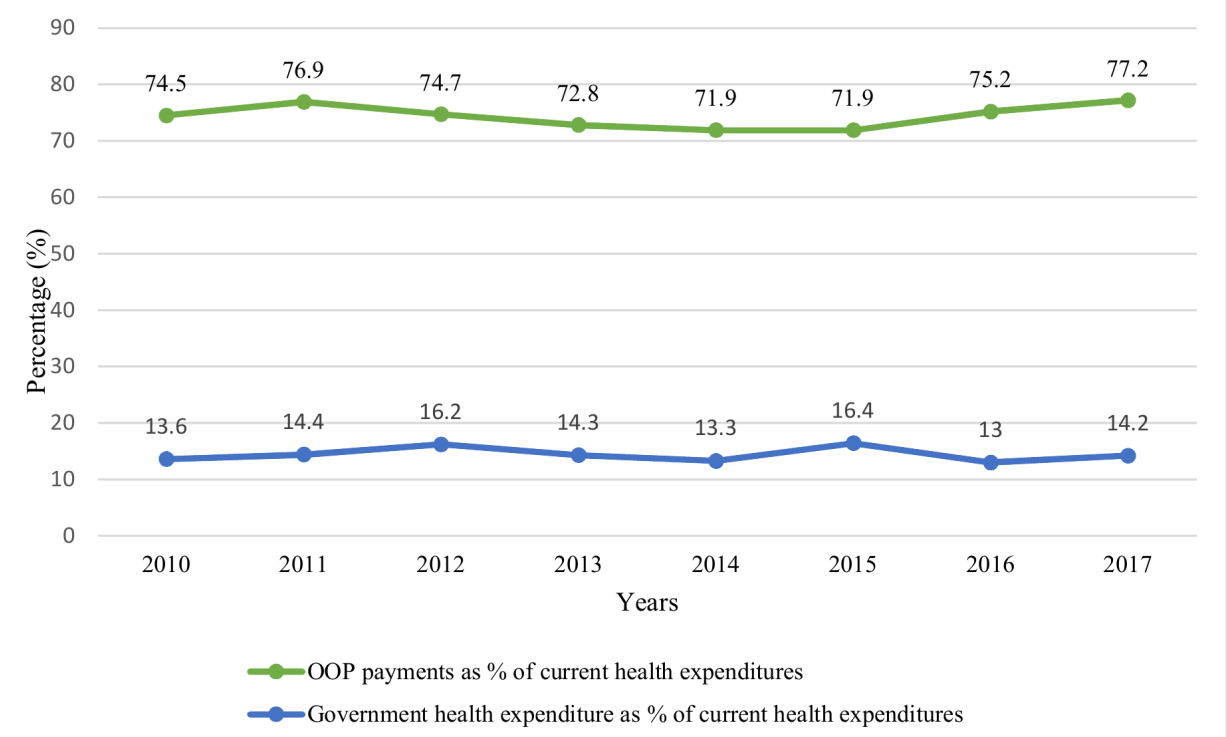

Figure 1 Percentage contribution of government health expenditure and OOP payments in current health expenditures in Nigeria (2010-2017). Approximately $74.5 \%$ of the total current health expenditure was financed through OOP payments in 2010 relative to about $13.6 \%$ government health expenditures as percentage of current health expenditures. The proportional contribution of OOP payments increased to $77.2 \%$ of current health spending in 2017 , which represented larger year-on-year burdens of OOP medical outlays on individuals and their families. In contrast, government health spending marginally increased from $13.6 \%$ to $14.2 \%$ of current health expenditures within the review period. Source: WHO: Global Health Observatory data repository. OOP, out-of-pocket.

countries in SSA, and as a result, the burden of medical payments is often disproportionately borne by individuals and their households. This constitutes large economic burdens for families and predisposes them to catastrophic healthcare payments and other impoverishment impacts of out-of-pocket (OOP) payments.

In Nigeria, the mechanism for financial protection against excessive medical payments is underdeveloped as only about $5 \%$ of the entire population is covered by the health insurance provided under the National Health Insurance Scheme. ${ }^{11} \mathrm{~A}$ study conducted to compare the level of UHC in three SSA countries, Ghana, Kenya and Nigeria, revealed that Nigeria had the lowest UHC of the countries, with $1.1 \%$ of the female population and $3.1 \%$ of the male population covered by social health insurance, respectively. ${ }^{12}$

Consequently, there has been an overdependence on OOP payments as the major source of healthcare financing in Nigeria, as revealed in figure 1.

In view of the rising levels of chronic disease like CVDs and the desire to achieve UHC by 2030 in the country, there is an increasing demand for research evidence in connection with the economic burden posed by OOP payments on patients. Therefore, this study aimed at estimating the OOP health expenditures (the direct and indirect costs) of treatment incurred by patients receiving outpatient and inpatient care in public and private hospital facilities in Ibadan, a Southwestern state in Nigeria. In addition, homecare cost for patients who required rehabilitative care after hospitalisation was estimated. Findings in the study will be useful for ascertaining the cost-effectiveness of the efforts to control modifiable risk factors for CVDs while also aiding the design of policy interventions for preventing the economic distress associated with OOP payments for medical services in Nigeria and in similar countries in SSA.

\section{MATERIALS AND METHODS \\ Study design}

This study used a descriptive cross-sectional study design.

\section{Description of study area}

Data were collected in the cardiology departments/ outpatient clinics of purposively selected private and public (secondary and tertiary), general and specialised, hospital facilities in Ibadan, Oyo State, South West, Nigeria. Ibadan is the capital of Oyo State. The city is also regarded as the third most populous city in Nigeria, behind Lagos and Kano. However, it is renowned as Nigeria's largest city in terms of geographical area. The city is situated within South West, Nigeria, $128 \mathrm{~km}$ inland northeast of Lagos and $350 \mathrm{~km}$ southwest of Abuja, the federal capital territory (FCT) of Nigeria. The residents and natives of the city are the Yorubas, although individuals from other ethnic groups across the country live in the city too. There are 11 local government areas (LGAs) in Ibadan which are stratified into 5 urban LGAs and 6 semiurban LGAs. Major healthcare facilities like the University College Hospital (UCH) and many other large public and private hospitals are located in Ibadan. These hospitals, especially UCH, serve as referral centres for other facilities in Oyo State and indeed, facilities in Nigeria as a whole. 


\section{Study population}

The study population consisted of individuals seeking healthcare related to heart conditions (CVDs) in private and public (secondary and tertiary), general and specialised, hospital facilities in Ibadan, Oyo State, South West, Nigeria.

\section{Inclusion and exclusion criteria}

Respondents were considered eligible to participate if he/she is 18 years and older and have been clinically confirmed to have any of the CVDs.

\section{Sampling technique}

Major hospitals that provide healthcare services for chronic diseases like CVDs are not widely spread across Ibadan city. They are clustered in a few urban and semiurban LGAs within the city. Therefore, those LGAs were purposively selected. Following this, the only tertiary hospital facility, UCH and two secondary hospitals in Ibadan, Adeoyo State Hospital and Jericho Specialist Hospital, were included in the study. Also, data were collected from all the specialised heart hospitals in the city. These facilities include Elyon Heart Rehabilitation Centre, Brofam Specialist Hospital and Fountain Heart Clinic. Therefore, a total sampling of all the 744 patients with CVD that attended the outpatient clinics of these hospital facilities between 4 November 2019 and 31 January 2020 was carried out. Details of the sample size calculation and sampling procedure are provided in the online supplemental material.

\section{Data collection}

Data were collected using a standardised survey questionnaire originally developed by Initiative for Cardiovascular Health Research in Developing Countries, which has been used in a previous study. ${ }^{13}$ This tool was adapted and designed using the REDcap software. ${ }^{14}$ The validity and reliability of the questionnaire was ensured by pretesting it in facilities that were similar to the ones included in the study. A total of 43 questionnaires, $10 \%$ of the estimated sample size, were administered for the pretest. Completed questionnaires were checked for completeness. The Cronbach alpha was used to test for internal consistency. From the results generated, necessary corrections were made accordingly. The instrument was then used to elicit information on respondents' demographic characteristics, medical history, individual and household economic information, OOP payments (ie, direct and indirect costs) incurred towards outpatient CVD treatment, inpatient care (for those hospitalised in the last 15 months prior to the study) as well as those who require home-based rehabilitative medical care. All the costs incurred per outpatient visit were elicited. The recall period for inpatient care was 15 months, while that for home-based rehabilitative care was 1 month, similar to that adopted in a previous study. ${ }^{13}$ Trained research assistants administered the research tool electronically using tablets after written informed consent was obtained from the participants. Strict data quality was ensured by the principal investigator and two data collection supervisors. Regular reviews of the data collected were conducted by reviewing hospital patient treatment records, especially to verify the costs of hospitalisation reported by patients. All the data collected were anonymised.

\section{Burden of OOP payments among patients with CVD}

This study adopted a microcosting of all the OOP payments incurred by patients towards accessing outpatient, inpatient and home-based medical services. This methodology for estimating the burden of OOP payments, that is, direct costs and indirect costs, follows that adopted in previous studies. ${ }^{115-20}$ Direct costs related to expenditures incurred when paying for hospital fees, purchase of medicines/drugs, transportation to and fro to access outpatient and inpatient treatment (also referred to as direct non-medical cost), medical consumables, laboratory tests, emergency room, hospital bed and radiological procedures. ${ }^{21}$ Similarly, indirect costs referred to the costs associated with loss of work/productivity/income as a result of sick days as well as the income/wages loss by the caregiver(s) who accompanied the patients to the clinic/ hospital. ${ }^{22-25}$ For outpatient and inpatient care, information were elicited from patients and/or patients' caregiver(s) to calculate the indirect cost. The number of days absent from work due to outpatient and inpatient care was multiplied by the patient's earnings per day. Following similar procedure, the wages lost for caregiving was also ascertained. No indirect costs were recorded for respondents/caregivers who were unemployed and those who had regular paid job because they may not have incurred any income loss due to CVD treatment. For patients with CVD who were self-employed, the average hourly/ daily earnings were elicited, and this was multiplied by the number of hours/days spent while undergoing treatment as a result of CVD. Estimated outpatient costs were annualised, while inpatient cost related to cost per hospitalisation. Home-based care costs included all the costs incurred for rehabilitative care outside of the hospital. Patients reported the average OOP payment incurred for home-based/rehabilitative care on a monthly basis and this cost was annualised. The presence of comorbidity could potentially bias the estimated costs upward, and to partially mitigate this effect, participants were asked to report on the OOP payments related to CVD treatment only, and, where necessary, guidance was sought from the attending physicians to ensure that possible effects of comorbidity were minimised.

\section{Outpatient 00P payments}

These include costs/payments for hospital charges, costs of drugs, laboratory costs and other costs which were associated with outpatient treatment.

\section{Inpatient 00P payments}

These include expenditures incurred for emergency room, hospital bed, treatment, surgery, purchase of 
drugs, laboratory tests, food expenses, costs of ambulance service and other costs incurred during index hospitalisation in the last 15 months.

Home-based/rehabilitative 00P payments

This includes doctor fees, nurse fees, physiotherapist costs, occupational rehabilitation, costs of drugs and laboratory costs.

\section{Statistical analysis}

Baseline characteristics of respondents was presented using percentages and proportions. The OOP payments for outpatient, inpatient and home-based medical services was reported as means \pm SDs. All quantitative data were analysed using STATA V.15 and costs/OOP payments were in Nigerian Naira (NGN ( $)$ ). The average US dollar to NGN at the time of data collection was $\$ 362.12$ per $\$ 1$. All through this article, the patient-perspective costs (direct and indirect) are used interchangeably with OOP medical payments.

\section{Patient and public involvement statement}

Apart from being research participants, there was no patient and/or public involvement in the design and execution of this study.

\section{RESULTS}

The background characteristics of respondents are depicted in table 1 . The highest number of patients with CVD were within age groups 55-64 years $(27.69 \%)$ and $65-74$ years $(30.11 \%)$. Respondents within ages below 45 years $(10.22 \%)$, age group $45-54$ years $(17.88)$ and those with ages above 74 years $(14.7 \%)$ were the lowest. Majority of the patients were women $(68.55 \%)$. Of the participants, $211(28.36 \%)$ had primary education; 184 (24.73\%) had secondary education; and 203 (27.28\%) had tertiary education, while 146 had no formal education. Also, 515 (69.22\%) were married; 200 (26.88\%) had lost his/her partner; 14 (1.88\%) were divorced; and 15 $(2.02 \%)$ were never married. Those who are self-employed (35.62\%) were the highest, and respondents who cannot work due to disability $(2.02 \%)$ were the fewest. The prevalence of participants who had ever smoke was $8.33 \%$, and only $9.19 \%$ of respondents consumed alcohol in the last 1 month prior to the time data were collected.

Table 2 shows the clinical/medical characteristics of the respondents. Majority of the patients were undergoing treatment due to hypertensive heart failure $(84.01 \%)$. This was followed by dilated cardiomyopathy $(4.44 \%)$, ischaemic heart disease $(3.9 \%)$ and anaemic heart failure $(2.15 \%)$, in that order. Of the 744 patients with CVD, 128 $(17.41 \%)$ were hospitalised in the last 15 months, and majority of them $(81.25 \%)$ were hospitalised once in the last 15 months, while only $2(1.56 \%)$ were hospitalised more than five times during that period. As such, the hospitalisation rate among this cohort of patients with

\begin{tabular}{|c|c|c|}
\hline Variable & Frequency & Per cent $(\%)$ \\
\hline \multicolumn{3}{|l|}{ Age group (years) } \\
\hline$<45$ & 76 & 10.22 \\
\hline $45-54$ & 133 & 17.88 \\
\hline $55-64$ & 206 & 27.69 \\
\hline $65-74$ & 224 & 30.11 \\
\hline$>74$ & 105 & 14.11 \\
\hline \multicolumn{3}{|l|}{ Gender } \\
\hline Male & 234 & 31.45 \\
\hline Female & 510 & 68.55 \\
\hline \multicolumn{3}{|l|}{ Educational level } \\
\hline None & 146 & 19.62 \\
\hline Primary & 211 & 28.36 \\
\hline Secondary & 184 & 24.73 \\
\hline Tertiary & 203 & 27.28 \\
\hline \multicolumn{3}{|l|}{ Marital status } \\
\hline Single & 15 & 2.02 \\
\hline Divorced/separated & 14 & 1.88 \\
\hline Widow/widower & 200 & 26.88 \\
\hline Married & 515 & 69.22 \\
\hline \multicolumn{3}{|l|}{ Occupation } \\
\hline Employed (government) & 65 & 8.74 \\
\hline Employed (non-government) & 19 & 2.55 \\
\hline Employed (self) & 265 & 35.62 \\
\hline Unemployed & 100 & 13.44 \\
\hline Retired & 152 & 20.43 \\
\hline Artisan & 128 & 17.2 \\
\hline Disabled/cannot work & 15 & 2.02 \\
\hline \multicolumn{3}{|l|}{ Ever smoked } \\
\hline No & 682 & 91.67 \\
\hline Yes & 62 & 8.33 \\
\hline \multicolumn{3}{|l|}{ Currently smoking } \\
\hline No & 61 & 98.39 \\
\hline Yes & 1 & 1.61 \\
\hline \multicolumn{3}{|l|}{ Ever consumed alcoholic drink } \\
\hline No & 559 & 75.13 \\
\hline Yes & 185 & 24.87 \\
\hline \multicolumn{3}{|c|}{ Consumed alcohol in the last 1 month } \\
\hline No & 168 & 90.81 \\
\hline Yes & 17 & 9.19 \\
\hline
\end{tabular}

CVD was $17.42 \%$. Also, for all the hospitalised patients, the average length of hospital stay was 8.2 days.

Estimates of annualised outpatient 00P payments

The OOP payment for different components of outpatient medical services among patients with CVDs by private and 
Table 2 Medical characteristics of respondents $(N=744)$

\begin{tabular}{lcc}
\hline Health issue & Frequency & $\begin{array}{l}\text { Per cent } \\
(\%)\end{array}$ \\
\hline Cardiovascular diseases & & \\
Alcoholic cardiomyopathy & 3 & 0.4 \\
Anaemic heart failure & 16 & 2.15 \\
Complete heart block & 6 & 0.81 \\
Congenital heart disease & 5 & 0.67 \\
Cor pulmonale & 1 & 0.13 \\
Dilated cardiomyopathy & 33 & 4.44 \\
\hline Hypertensive heart disease & 625 & 84.01 \\
Ischaemic heart disease & 29 & 3.9 \\
\hline Pericardial valvular heart disease & 7 & 0.94 \\
\hline Peripartum cardiomyopathy & 5 & 0.67 \\
\hline Thyroid disease & 3 & 0.4 \\
\hline Other & 11 & 1.48
\end{tabular}

Hospitalised in the last 15 months?

\begin{tabular}{|ccc|}
\hline No & 607 & 82.59 \\
\hline Yes & 128 & 17.41 \\
\hline Numer of times hospitalised & & \\
\hline Once & 104 & 81.25 \\
\hline Twice & 18 & 14.06 \\
\hline Thrice & 4 & 3.13 \\
\hline Five times & 2 & 1.56 \\
\hline LoHS (days) & & \\
\hline $1-3$ & 13 & 10.16 \\
\hline $4-6$ & 26 & 20.31 \\
\hline $7-9$ & 38 & 29.69 \\
\hline $10-12$ & 16 & 12.5 \\
\hline 12 & 35 & 27.34 \\
\hline Average LoHS & 8.2 days \\
\hline
\end{tabular}

LoHS, length of hospital stay.

public (federal and state) hospital facilities are reported in table 3 . The cost of laboratory test was the highest relative to other components of OOP payments in private and federal-owned hospital facilities, $\$ 535042.1 \pm \$ 6226$ $830.4(\$ 1477.5 \pm \$ 1719.6)$ and $265091.7 \pm 3968390.7$ $(\$ 732.1 \pm \$ 1095.9)$, respectively. For patients who accessed healthcare in state-owned hospital facilities, the cost of drugs/medicines was the highest when compared with other components of OOP payments, $238917.4 \pm 886$ 081.5 (\$659.8 $\$ 2446.9)$. As expected, the annual average OOP payments in private hospitals was higher than that incurred in public hospitals (both federal-owned and state-owned hospitals): 2283515.8 (\$782.9) for private hospital facilities; 115593.5 (\$319.2) for federal-owned hospital; 85959.1 (\$237.4). Across all the hospital facilities, the annual direct and indirect costs were 421 $595.7 \pm 855962.0$ (\$1164.2_\$2363.8) and $\$ 19$ 146.5 $\$ 53$
$610.1(\$ 52.87 \pm \$ 148.05)$. Estimated OOP payments are heavy-tailed to the right, hence the higher value of the SD from the mean.

\section{Estimates of 00P payments per hospitalisation}

Table 4 shows the OOP payment per hospitalisation among patients with CVD. The cost of treatment, 68 $428.57 \pm 108814.60$ ( $\$ 188.97 \pm \$ 300.49)$, was the highest in private hospitals, followed by the cost of laboratory tests, $\$ 51$ 428.57 $\$ 55$ 280.67. In the federal-owned facility, OOP payments for surgical procedure was the highest, $\$ 3414000.0$ (\$9429.8), and this was followed by the costs of laboratory tests, $78 \quad 456.55 \pm 99141.23$ (\$216.66 \pm \$273.78). This was followed by the costs of treatment and the costs of drugs, 49 577.62 91 $349.57(\$ 136.91 \pm \$ 252.26)$ and $\$ 47050.60 \pm \$ 64373.54$ $(\$ 129.93 \pm \$ 177.11)$, respectively. Similarly, the costs of laboratory test and OOP payments to purchase drugs per hospitalisation were the largest in state-owned hospitals. Following a similar pattern to the OOP payments for outpatient care, patients who attended state hospitals incurred the least OOP payment per an episode of hospitalisation, 075.67 ( $\$ 251.51$ ), relative to those who accessed care in private and federal hospitals, 193 665.71 (\$534.81) and \$254 559.19 (\$702.97). Relative to that of outpatient care, patients with CVD who were admitted in the Federal hospital, incurred the highest OOP payment. Overall, the average direct and indirect OOP payments per hospitalisation across all facilities were $182302.4 \pm 249090.4(\$ 503.43 \pm \$ 687.87)$ and $\$ 14$ $700.8 \pm 69297.1$ (\$40.60 $\$ 191.37$ ), respectively. Components of total OOP payments for hospitalised patients with cardiovascular disease as computed by the author are reported in figure 2 .

\section{Estimates of 00P payments for home-based/rehabilitative care}

The annualised OOP payment incurred by patients with CVD who required rehabilitative care is reported in table 5. The highest cost incurred was physiotherapy costs, 144 $000.0 \pm \$ 401905.8$ (\$397.66 $\$ \$ 1109.87)$, followed by the cost of drugs, $335161.8 \pm 3334195.4(\$ 97.10 \pm \$ 922.89)$. The average rehabilitative cost was $\$ 012.0$ (\$82.88).

\section{DISCUSSION}

This study estimated the OOP payments (direct and indirect costs) incurred to access outpatient, inpatient and rehabilitative care among patients with CVD attending private and public healthcare facilities in Ibadan, Nigeria. As such, the study fills an important gap in the literature by providing estimates of the financial burden of treating heart-related diseases, entirely from patients' perspective. For the first time, all possible OOP expenditures relating to outpatient, hospitalisation as well as rehabilitative care incurred by individuals ailing from a wide range of CVDs were estimated. This provides policymakers with a comprehensive source of information with overarching 
Table 3 Annualised out-of-pocket payment for outpatient treatment among patients with cardiovascular disease

\begin{tabular}{|c|c|c|c|c|c|}
\hline Hospital type & $\begin{array}{l}\text { Respondents } \\
\text { (n) }\end{array}$ & $\begin{array}{l}\text { Minimum } \\
\text { cost ( })\end{array}$ & $\begin{array}{l}\text { Maximum } \\
\text { cost (\#) }\end{array}$ & Mean cost ( & SD ( \\
\hline \multicolumn{6}{|l|}{ Private } \\
\hline Hospital charges & 38 & 0.0 & 90000.0 & 51978.9 & 20366.8 \\
\hline Lab test cost & 38 & 0.0 & 2400000.0 & 535042.1 & 622683.4 \\
\hline Cost of drug & 38 & 14400.0 & 3974400.0 & 529357.9 & 844813.3 \\
\hline Other medical costs & 38 & 0.0 & 384000.0 & 17684.2 & 65785.1 \\
\hline Average cost & & & & 283515.8 & \\
\hline \multicolumn{6}{|l|}{ Federal } \\
\hline Hospital charges & 338 & 0.0 & 42000.0 & 15571.6 & 7213.0 \\
\hline Lab test cost & 338 & 0.0 & 2400000.0 & 265091.7 & 396839.7 \\
\hline Cost of drug & 338 & 0.0 & 3360000.0 & 176600.7 & 293799.6 \\
\hline Other medical costs & 324 & 0.0 & 150000.0 & 5110.0 & 17084.5 \\
\hline Average cost & & & & 115593.5 & \\
\hline \multicolumn{6}{|l|}{ State } \\
\hline Hospital charges & 368 & 0.0 & 25200.0 & 3135.3 & 2498.9 \\
\hline Lab test cost & 368 & 0.0 & 1440000.0 & 95701.6 & 185896.8 \\
\hline Cost of drug & 368 & 0.0 & 1210000.0 & 238917.4 & 886081.5 \\
\hline Other medical costs & 359 & 0.0 & 259200.0 & 6082.2 & 27118.9 \\
\hline Average cost & & & & 85959.1 & \\
\hline Average direct outpatient cost (all facilities) & & & & 421595.7 & 855962.0 \\
\hline Average indirect outpatient cost (all facilities) & & & & 19146.5 & 53610.1 \\
\hline
\end{tabular}

implications for healthcare financing in Nigeria and in SSA as a whole.

Regarding the baseline profile of patients with CVD in this study, majority were within the age range of 45-74 years. This is consistent with findings in previous studies that most chronic non-communicable diseases, especially CVDs, manifest earlier and during the most productive ages of individuals in low-income countries compared with what is obtainable in high-income countries. ${ }^{26-29}$ Also, the prevalence of CVDs was higher among women relative to men, a finding which has also been revealed in earlier studies. ${ }^{29}{ }^{30}$ Hypertensive heart failure and ischaemic heart disease were the predominant diagnostic conditions relative to other types of CVDs. A study conducted to investigate the profile of acute heart failure in a tertiary hospital in Abeokuta, Nigeria, reported that hypertensive heart failure was the the most common heart condition (about $78.5 \%$ of all cases) observed in the study. ${ }^{31}$ Another study assessed the pattern of CVDs in Abuja, the FCT of Nigeria and compared this pattern with that of a similar study implemented in South Africa, the Heart of Soweto Study. The study reported that hypertensive heart failure was the predominant (ie, $61 \%$ of the cases) diagnostic condition among patients with CVD and that heart-related patients in Abuja were twice likely to present with hypertensive heart disease relative to that observed in the South African study. ${ }^{32}$
The OOP payment incurred by patients with CVD who accessed outpatient healthcare services in private hospital facilities was higher on average, relative to those who were treated in public hospitals. The average OOP payment expended by patients who attended private hospitals was almost three times that incurred by patients who were treated in the federal-owned/tertiary hospital. Patients who accessed treatment in the state-owned hospitals incurred the least average outpatient costs per year. Apparently, the fact that private facilities are driven by the aim of maximising profit is enough reason to charge higher fees for healthcare services. Another justification for the differences in OOP payments in private and public hospitals is that patients who accessed healthcare services in public hospitals enjoy subsidised charges. However, these reduced treatment fees oftentimes impose a huge financial burden on individuals and families, especially the poor ones. Also, patients are sometimes weary of accessing healthcare in public-owned facilities due to long waiting time and poor infrastructure as these hospitals are usually overstretched as a result of high hospital attendance rate.

A different pattern was shown for OOP payment per hospitalisation. It was observed that all severe cases of CVDs hospitalisations (ie, those requiring surgery) were managed in the federal-owned hospital. This is because tertiary hospital facilities have a higher number 
Table 4 Out-of-pocket payment per hospitalisation among patients with cardiovascular disease

\begin{tabular}{|c|c|c|c|c|c|}
\hline Hospital type & $\begin{array}{l}\text { Respondents } \\
\text { (n) }\end{array}$ & Minimum cost ( & Maximum cost ( & Mean cost ( & SD (\#) \\
\hline \multicolumn{6}{|l|}{ Private } \\
\hline Emergency room & 7 & 0.00 & 0.00 & 0.00 & 0.00 \\
\hline Hospital bed & 7 & 0.00 & 30000.00 & 6442.86 & 10752.34 \\
\hline Treatment & 7 & 0.00 & 300000.00 & 68428.57 & 108814.60 \\
\hline Surgery & 7 & 0.00 & 0.00 & 0.00 & 0.00 \\
\hline Cost of drug & 7 & 0.00 & 50000.00 & 23571.43 & 20354.01 \\
\hline Lab test cost & 7 & 0.00 & 160000.00 & 51428.57 & 55280.67 \\
\hline Food expenses & 7 & 0.00 & 7000.00 & 1964.29 & 2451.31 \\
\hline Cost of ambulance & 5 & 0.00 & 0.00 & 0.00 & 0.00 \\
\hline Other medical costs & 5 & 0.00 & 184150.00 & 41830.00 & 79980.43 \\
\hline Average cost & & & & 193665.71 & \\
\hline \multicolumn{6}{|l|}{ Federal } \\
\hline Emergency room & 83 & 0.00 & 20000.00 & 872.29 & 3430.90 \\
\hline Hospital bed & 84 & 0.00 & 1680000.00 & 28651.19 & 182802.10 \\
\hline Treatment & 84 & 0.00 & 500000.00 & 49577.62 & 91349.57 \\
\hline Surgery & 10 & 1440000 & 5400000.0 & 3414000.0 & 5400000 \\
\hline Cost of drug & 84 & 0.00 & 400000.00 & 47050.60 & 64373.54 \\
\hline Lab test cost & 84 & 0.00 & 450000.00 & 78456.55 & 99141.23 \\
\hline Food expenses & 84 & 0.00 & 100000.00 & 6696.43 & 14935.59 \\
\hline Cost of ambulance & 76 & 0.00 & 2500.00 & 32.89 & 286.77 \\
\hline Other medical costs & 78 & 0.00 & 250000.00 & 9352.56 & 29655.76 \\
\hline Average cost & & & & 752339.3 & \\
\hline \multicolumn{6}{|l|}{ State } \\
\hline Emergency room & 37 & 0.00 & 15000.00 & 675.68 & 2677.62 \\
\hline Hospital bed & 37 & 0.00 & 56000.00 & 4808.11 & 9937.68 \\
\hline Treatment & 37 & 0.00 & 400000.00 & 36891.89 & 80026.31 \\
\hline Surgery & 37 & 0.00 & 0.00 & 0.00 & 0.00 \\
\hline Cost of drug & 37 & 0.00 & 105000.00 & 20794.59 & 20575.74 \\
\hline Lab test cost & 37 & 0.00 & 100000.00 & 23540.54 & 23462.26 \\
\hline Food expenses & 37 & 0.00 & 56000.00 & 2689.19 & 9275.90 \\
\hline Cost of ambulance & 37 & 0.00 & 0.00 & 0.00 & 0.00 \\
\hline Other medical costs & 37 & 0.00 & 31500.00 & 1675.68 & 5408.61 \\
\hline Average cost & & & & 91075.67 & \\
\hline $\begin{array}{l}\text { Average direct outpatient } \\
\text { cost (all facilities) }\end{array}$ & & & & 182302.4 & 249090.4 \\
\hline $\begin{array}{l}\text { Average indirect outpatient } \\
\text { cost (all facilities) }\end{array}$ & & & & 14700.8 & 69297.1 \\
\hline
\end{tabular}

of physicians with different expertise compared with the resources available in private and state-owned facilities. Presumably, this had impact on the average OOP payment per hospitalisation incurred in federal-owned facility as this was the highest relative to that incurred in private and state-owned hospitals.

In general, the contribution of different cost categories as a proportion of total OOP payments by hospital type was examined. The costs of drugs and laboratory tests were particularly high in all the facilities. An earlier study on the economic burden of heart failure in Abeokuta, Nigeria, revealed that the cost of drugs and transportation represent about $90 \%$ of total costs. ${ }^{19}$ Also, another study conducted in a similar SSA country found that the cost of drugs was about $50 \%$ of the total OOP expenditures incurred by patients. ${ }^{16}$ This implies that the cost of purchasing medicines among patients with CVD represented a significant financial burden for patients. In 


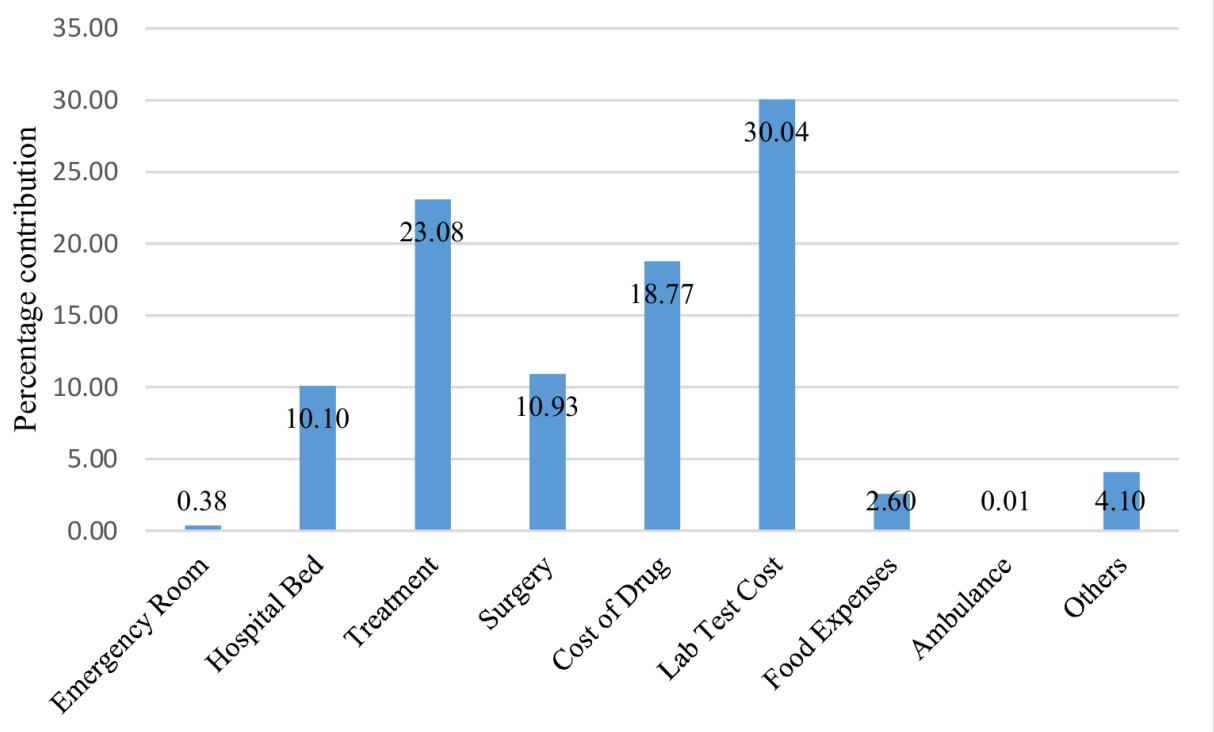

Figure 2 Components of total OOP payments for hospitalised patients with cardiovascular disease. OOP payments for accessing healthcare among hospitalised patients across all the hospitals were combined. The cost of laboratory test was $30 \%$ of the total OOP payments incurred by patients. Also, $23.08 \%$ of medical expenditures was devoted to paying for hospital treatment. Payments for emergency room $(0.38 \%)$ and ambulance $(0.01 \%)$ were the lowest. OOP, out-of-pocket.

addition, this present study also revealed that the costs of laboratory tests are equally substantial in connection with outpatient OOP payments. This finding is not unexpected because in some cases, the equipment used for carrying out laboratory tests can be in short supply in hospital facilities in Nigeria. Where the equipment is available, the costs of laboratory tests can sometimes be quite expensive for patients. Another reason for the significant contribution of laboratory costs to the overall OOP payments in this study is that sometimes patients may need to travel to another hospital facility located within or outside the state where they are being managed to have access to laboratory test services. The costs of transportation will usually serve to increase the overall OOP expenditures incurred for laboratory tests.

Comparing the average OOP payments incurred across federal-owned, state-owned and private-owned hospitals, the outpatient costs were expectedly the highest in private hospitals. However, it was observed that all the cases/patients requiring surgery during inpatient stay accessed the federal owned hospital, and as a result, the average costs of accessing inpatient care in the federalowned hospital were substantially higher relative to the mean costs incurred in state-owned and privately owned hospital facilities. This gap was due to the huge costs of surgeries. Evidence in this study also showed that the OOP payments incurred in public hospital facilities remain high against the expectation that the costs of healthcare services should be much cheaper in those facilities. This represents a cause for concern, and the government needs to do more regarding the efforts towards ensuring UHC in Nigeria.

In general, the average direct OOP payments for outpatient and inpatient healthcare services across all facilities were $421595.7 \pm 855962.0(\$ 1164.2 \pm 2363.8)$ and $\$ 421595.7 \pm 855962.0$ (\$1164.2 $\$ 2363.8)$. These seem very high in a country where almost 89.2 million (ie, $40.1 \%$ of the entire population) are adjudged to be poor. ${ }^{33} \mathrm{On}$

Table 5 Annualised out-of-pocket payments for home-based/rehabilitative care among patients with cardiovascular disease

\begin{tabular}{lllcrr}
\hline Cost components & $\begin{array}{l}\text { Respondents } \\
(\mathbf{n})\end{array}$ & Minimum cost (\#) & Maximum cost (\#) & Mean cost (\#) & SD (\#) \\
\hline Doctor fee & 355 & 0.0 & 60000.0 & 459.7 & 4256.5 \\
\hline Nurse fee & 336 & 0.0 & 600000.0 & 2035.7 & 32855.7 \\
\hline Lab test & 336 & 0.0 & 118020.0 & 15428.6 & 106186.6 \\
\hline Cost of drug & 335 & 0.0 & 600000.0 & 35161.8 & 334195.4 \\
\hline Occupational rehabilitation & 334 & 0.0 & 276000.0 & 9556.9 & 152789.1 \\
\hline Physiotherapist cost & 334 & 0.0 & 1440000.0 & 144000.0 & 401905.8 \\
Other medical cost & 333 & 0.0 & 360000.0 & 3441.4 & 29510.7 \\
\hline Average cost & & & & 30012.0 & \\
\hline
\end{tabular}


the other hand, the low contribution of indirect cost to total cost is indicative of the level of unemployment as many of the patients and their caregivers reported little income loss due to sick days.

Among the patients who needed rehabilitative care at home, physiotherapy cost was the major OOP payment made which is reasonable since most patients with CVD may require physiotherapy sessions after hospitalisation in order to regain the ability to engage in basic activities of daily living that might have been affected by illness. Compared with the average OOP payments incurred for outpatient and inpatient healthcare services among patients with CVD, the average costs incurred for homebased/rehabilitative care are much lower. This shows that majority of the OOP payments borne by patients with CVD are incurred for accessing outpatient and inpatient care services in Nigeria.

\section{Strengths and limitation of the study}

Compared with earlier studies conducted in Nigeria, the implementation of this study is methodologically robust as it attempted to avoid some of the weaknesses observed in the few previous studies reviewed. However, there are some limitations that are noteworthy. The OOP payments elicited for hospitalised patients with CVD may have been underestimated since data were collected after the patients were discharged to avoid bogging the patients and/or their caregivers at a time when they are seriously ill and hospitalised. Despite this, attempts were made to ensure that the estimates were as accurate as possible by verifying the inpatient $\mathrm{OOP}$ payments incurred by patients from hospital records. In addition, there were no follow-ups on individual patients, which would have been beneficial for capturing other OOP payments over a longer period. However, this was not possible due to the design and duration of the study. Despite the efforts to reduce the effects of comorbidity/multimorbidity on the estimated costs, it is not unlikely that some level of bias remains. Lastly, the conceptualisation of indirect costs in this study is a narrow one. Other indirect costs which relates to reduced healthcare and loss of employment for other family members, as well as reduced school attendance of children, were not included in the calculation of indirect costs. This may mean that the indirect cost is quite higher than what is reported in the study. Therefore, these limitations should be considered when interpreting the findings of this study.

\section{CONCLUSION}

The burden of OOP payment among patients with CVD is high as revealed in this study. This could further expose patients and their families to financial hardship, which will be detrimental to achieving the twin target of poverty eradication and good health as articulated in the Sustainable Development Goals. Therefore, there is a need to increase efforts to achieve UHC in Nigeria.
Contributors FA conceived the idea, designed the study, collected and analysed the data, and wrote the manuscript.

Funding This research was supported by the Consortium for Advanced Research Training in Africa (CARTA). CARTA is jointly led by the African Population and Health Research Center and the University of the Witwatersrand and funded by the Carnegie Corporation of New York (Grant No-G-19-57145), Sida (Grant number 54100113), Uppasala Monitoring Centre and the DELTAS Africa Initiative (Grant No: 107768/Z/15/Z). The DELTAS Africa Initiative is an independent funding scheme of the African Academy of Sciences (AAS)'s Alliance for Accelerating Excellence in Science in Africa (AESA) and supported by the New Partnership for Africa's Development Planning and Coordinating Agency (NEPAD Agency) with funding from the Wellcome Trust (UK) and the UK government. The statements made and views expressed are solely the responsibility of the Fellow.

Competing interests None declared.

Patient consent for publication Not required.

Ethics approval This study involved human subjects and necessary ethical procedures were followed. Ethical approval was obtained from the ethics review committee of the University of Ibadan/University College Hospital (NHREC/05/01/2008a). Approval was also obtained from respective hospital facilities.

Provenance and peer review Not commissioned; externally peer reviewed.

Data availability statement The data used for this study will be available on reasonable request from the corresponding author.

Supplemental material This content has been supplied by the author(s). It has not been vetted by BMJ Publishing Group Limited (BMJ) and may not have been peer-reviewed. Any opinions or recommendations discussed are solely those of the author(s) and are not endorsed by BMJ. BMJ disclaims all liability and responsibility arising from any reliance placed on the content. Where the content includes any translated material, BMJ does not warrant the accuracy and reliability of the translations (including but not limited to local regulations, clinical guidelines, terminology, drug names and drug dosages), and is not responsible for any error and/or omissions arising from translation and adaptation or otherwise.

Open access This is an open access article distributed in accordance with the Creative Commons Attribution Non Commercial (CC BY-NC 4.0) license, which permits others to distribute, remix, adapt, build upon this work non-commercially, and license their derivative works on different terms, provided the original work is properly cited, appropriate credit is given, any changes made indicated, and the use is non-commercial. See: http://creativecommons.org/licenses/by-nc/4.0/.

ORCID iD

Folashayo Adeniji http://orcid.org/0000-0002-4697-3081

\section{REFERENCES}

1 Balbinotto Neto G, Silva ENda. The costs of cardiovascular disease in Brazil: a brief economic comment. Arq Bras Cardiol 2008;91:198-9.

2 Abegunde DO, Mathers CD, Adam T, et al. The burden and costs of chronic diseases in low-income and middle-income countries. Lancet 2007;370:1929-38.

3 Martiniuk ALC, Lee CMY, Lawes CMM, et al. Hypertension: its prevalence and population-attributable fraction for mortality from cardiovascular disease in the Asia-Pacific region. J Hypertens 2007;25:73-9.

4 Opie LH, Mayosi BM. Cardiovascular disease in sub-Saharan Africa.

5 Kengne AP, Ntyintyane LM, Mayosi BM. A systematic overview of prospective cohort studies of cardiovascular disease in sub-Saharan Africa. Cardiovasc J Afr 2012;23:103-12.

6 Godwin KM, Wasserman J, Ostwald SK. Cost associated with stroke: outpatient rehabilitative services and medication. Top Stroke Rehabil 2011;18:676-84.

7 Cappuccio FP, Miller MA. Cardiovascular disease and hypertension in sub-Saharan Africa: burden, risk and interventions. Intern Emerg Med 2016;11:299-305.

8 Mocumbi AO. Lack of focus on cardiovascular disease in subSaharan Africa. Cardiovasc Diagn Ther 2012;2:74.

9 Hamid S, Groot W, Pavlova M. Trends in cardiovascular diseases and associated risks in sub-Saharan Africa: a review of the evidence for Ghana, Nigeria, South Africa, Sudan and Tanzania. Aging Male 2019;22:169-76. 
10 Yuyun MF, Sliwa K, Kengne AP, et al. Cardiovascular diseases in Sub-Saharan Africa compared to high-income countries: an epidemiological perspective. Glob Heart 2020;15:15.

11 Okpani Al, Abimbola S. Operationalizing universal health coverage in Nigeria through social health insurance. Niger Med J 2015;56:305.

12 Amu H, Dickson KS, Kumi-Kyereme A, et al. Understanding variations in health insurance coverage in Ghana, Kenya, Nigeria, and Tanzania: evidence from demographic and health surveys. PLoS One 2018;13:e0201833.

13 Huffman MD, Rao KD, Pichon-Riviere A, et al. A cross-sectional study of the microeconomic impact of cardiovascular disease hospitalization in four low- and middle-income countries. PLoS One 2011;6:e20821.

14 Patridge EF, Bardyn TP. Research electronic data capture (REDCap). J Med Library Assoc 2018;106:142.

15 Kernick DP, Reinhold DM, Netten A. What does it cost the patient to see the doctor? Br J Gen Pract 2000;50:401-3.

16 Tolla MT, Norheim OF, Verguet S, et al. Out-of-pocket expenditures for prevention and treatment of cardiovascular disease in general and specialised cardiac hospitals in Addis Ababa, Ethiopia: a crosssectional cohort study. BMJ Glob Health 2017;2:e000280.

17 Brandle M, Zhou H, Smith BRK, et al. The direct medical cost of type 2 diabetes. Diabetes Care 2003;26:2300-4.

18 Le C, Zhankun S, Jun D, et al. The economic burden of hypertension in rural south-west China. Trop Med Int Health 2012;17:1544-51.

19 Ogah OS, Stewart S, Onwujekwe OE, et al. Economic burden of heart failure: investigating outpatient and inpatient costs in Abeokuta, Southwest Nigeria. PLoS One 2014;9:e113032.

20 Zhou Z-Y, Koerper MA, Johnson KA, et al. Burden of illness: direct and indirect costs among persons with hemophilia $A$ in the United States. J Med Econ 2015;18:457-65.

21 Eisemberg JM. Clinical economics: a guide to the economic analysis of clinical practices. Jama, 1989 Nov 24 262(20): 2879-86.

22 Xie F, Thumboo J, Fong K-Y, et al. A study on indirect and Intangible costs for patients with knee osteoarthritis in Singapore. Value in Health 2008;11:S84-90.
23 Dee A, Kearns K, O'Neill C, et al. The direct and indirect costs of both overweight and obesity: a systematic review. BMC Res Notes 2014;7:242.

24 Ratcliffe J. The measurement of indirect costs and benefits in health care evaluation: a critical review. Project Appraisal 1995;10:13-18.

25 Etiaba $\mathrm{E}$, Onwujekwe $\mathrm{O}$, Torpey $\mathrm{K}$, et al. What is the economic burden of subsidized HIV/AIDS treatment services on patients in Nigeria and is this burden catastrophic to households? PLoS One 2016;11:e0167117.

26 Dalal S, Beunza JJ, Volmink J, et al. Non-communicable diseases in sub-Saharan Africa: what we know now. Int $J$ Epidemiol 2011;40:885-901.

27 Asaria P, Chisholm D, Mathers C. Chronic diseases 3 chronic disease prevention health eff ects and FI nancial costsa 2007;370:2044-53

28 Adeniji F. Chronic disease profile, health utilization and self-reported financial situation of older people in rural South Africa. Int J Aging Res 2019;2:1-15.

29 Holmes MD, Dalal S, Volmink J, et al. Non-communicable diseases in sub-Saharan Africa: the case for cohort studies. PLoS Med 2010;7:e1000244.

30 Yusuf S, Reddy S, Ônpuu S, et al. Global burden of cardiovascular diseases: part I: general considerations, the epidemiologic transition, risk factors, and impact of urbanization. Circulation 2001;104:2746-53

31 Ogah OS, Stewart S, Falase AO, et al. Contemporary profile of acute heart failure in Southern Nigeria. JACC Heart Fail 2014;2:250-9.

32 Ojji D, Stewart S, Ajayi S, et al. A predominance of hypertensive heart failure in the Abuja Heart Study cohort of urban Nigerians: a prospective clinical registry of 1515 de novo cases. Eur J Heart Fail 2013;15:835-42.

33 National Bureau of Staistics. Poverty and inequality in Nigeria, 2019. Available: https://nigerianstat.gov.ng/elibrary? queries[search]=poverty [Accessed 28 Jul 2020]. 